\title{
A contribuição do espraiamento urbano de Brasília para a fragmentação da paisagem de Cerrado ao redor da cidade
}

\author{
The contribution of Brasilia's urban sprawl to the \\ fragmentation of the Brazilian Cerrado around the city
}

Priscila Pimentel Jacob [a] [D, José Augusto Drummond [a] $[\mathrm{D}$ )

Cristiane Gomes Barreto [a] [iD)

[a] Universidade de Brasília (UnB), Centro de Desenvolvimento Sustentável (CDS), Brasília, DF, Brasil

Como citar: Jacob, P. P., Drummond, J. A., \& Barreto, C. G. (2021). A contribuição do espraiamento urbano de Brasília para a fragmentação da paisagem de Cerrado ao redor da cidade. urbe. Revista Brasileira de Gestão Urbana, v.13, e20200420. https://doi.org/10.1590/2175-3369.013.e20200420

\section{Resumo}

Este artigo avalia, por meio de métricas da paisagem, a fragmentação do Cerrado causada pelo espraiamento urbano de Brasília. Três análises compõem o estudo: i) análise diacrônica, ii) análise sincrônica; e iii) cenário de não espraiamento urbano da cidade. A análise diacrônica (1953-2013) estuda as transformações da paisagem do Distrito Federal com foco nas áreas urbanas e naturais. A análise sincrônica compara as densidades e as compacidades urbanas das concentrações urbanas brasileiras de caráter metropolitano (São Paulo/SP, Rio de Janeiro/RJ, Belo Horizonte/BH, Recife/PE, Porto Alegre/RS, Salvador/BA, Brasília/DF, Fortaleza/CE e Curitiba/PR) para o ano de 2015. 0 cenário hipotético de não espraiamento urbano de Brasília mostra a forma e o tamanho que a cidade poderia ter caso fosse mais densa e compacta. Os resultados indicam que um cenário urbano mais denso e compacto poderia ter preservado mais a paisagem natural da cidade.

Palavras-chave: Fragmentação da Paisagem. Espraiamento Urbano. Compacidade Urbana. Brasília. Cerrado.

\section{Abstract}

This paper assesses, using landscape metrics, the fragmentation of the Brazilian Cerrado caused by Brasília's urban sprawl. The study is divided into three analysis: i) diachronic analysis; ii) synchronic analysis; and iii) scenario of non-urban sprawling of the city. The diachronic analysis (1953-2013) studies the Distrito Federal's landscape transformations focusing on urban areas and on natural areas. The synchronic analysis compares urban densities and urban compactness in Brazilian's metropolitan areas (São Paulo / SP, Rio de Janeiro / RJ, Belo Horizonte / BH, Recife / PE, Porto Alegre / RS, Salvador / BA, Brasília / DF, Fortaleza / CE and Curitiba / $P R)$ in 2015. The hypothetical scenario of Brasilia's non-urban sprawling shows the shape and size that the city

PPJ é arquiteta e urbanista, mestra em Desenvolvimento Sustentável, e-mail: priscilajacob@gmail.com JAD é cientista socioambiental, professor titular, Ph. D. em Land Resources, e-mail: jaldrummond@uol.com.br CGB é bióloga, professora adjunta, doutora em Política e Gestão, e-mail: crisbarreto@unb.br 
could have if it were denser and more compact. Results indicate that a denser and more compact urban scenario could have preserved more of the city's natural landscape.

Keywords: Landscape Fragmentation. Urban Sprawl. Urban Compactness. Brasília. Cerrado.

\section{Introdução}

A transferência da capital federal brasileira do Rio de Janeiro para Brasília, realizada durante a presidência de Juscelino Kubitschek (1956-1961), transformou radicalmente paisagem natural do Distrito Federal (DF). Em 1953, antes da construção de Brasília, o Cerrado lato sensu representava 99,94\% da paisagem total do DF enquanto as áreas agrícola e urbana cobriam apenas 0,02\% cada (Unesco, 2002). Em 2019, 66 anos depois, o cenário era bem diferente: 43,81\% de Cerrado lato sensu, 44,38\% de áreas agrícolas e 10,14\% de áreas urbanas (Mapbiomas, 2020). Esses dados mostram que a supressão da paisagem natural no DF tem como principal fator a agricultura. No entanto, a urbanização também é um fator relevante para o processo - especialmente como força motriz de toda a ocupação do território - e necessita uma análise e uma avaliação crítica. Esta pesquisa busca contribuir para essa análise e essa reflexão.

Como a paisagem anterior à construção de Brasília era predominantemente de Cerrado, algum impacto ambiental do empreendimento era esperado. No entanto, a morfologia da cidade influenciou o grau desse impacto. A hipótese aqui levantada é que o espraiamento urbano (urban sprawl) de Brasília agravou esse impacto e que um cenário urbano mais denso e compacto poderia ter fragmentado menos a paisagem natural ao redor da cidade.

O objetivo geral desta pesquisa é avaliar a fragmentação da paisagem de Cerrado decorrente do espraiamento urbano de Brasília. Os objetivos específicos são: i) avaliar as transformações na paisagem natural de Cerrado decorrentes do espraiamento urbano de Brasília; ii) contrastar o espraiamento de Brasília com a morfologia urbana de outras metrópoles brasileiras; e iii) criar um cenário hipotético de não espraiamento de Brasília. A avaliação das transformações na paisagem natural de Cerrado decorrentes do espraiamento urbano de Brasília consiste numa análise diacrônica da paisagem do DF entre 1953 e 2013. Essa análise possibilita um estudo multitemporal das diferentes paisagens do DF ao longo do tempo. A comparação do espraiamento de Brasília com a morfologia urbana de outras metrópoles brasileiras consiste numa análise sincrônica da morfologia urbana das metrópoles brasileiras para o ano de 2015. Essa análise possibilita um estudo multiespacial das diferentes metrópoles brasileiras num mesmo momento. A criação de um cenário hipotético de não espraiamento de Brasília ilustra como um crescimento urbano mais denso e compacto da cidade possibilitaria uma melhor preservação da paisagem natural como um todo.

Este artigo inova ao aplicar a análise da ecologia da paisagem a um estudo urbano sobre Brasília. Essa articulação possibilita uma análise mais holística da paisagem. Além disso, a análise quantitativa das métricas de paisagem confere uma objetividade maior à discussão. Espera-se que este estudo contribua para a formação de um olhar mais crítico acerca das implicações da morfologia das cidades para o meio ambiente natural ao redor delas.

\section{Referencial teórico}

Estudos da biologia da conservação apontam a antropização do meio ambiente natural como uma das maiores causas de extinção de espécies (Wilson, 1999; Dirzo et al., 2014). Calcula-se que os humanos tenham acelerado a taxa de extinção natural de espécies em mil vezes (Pimm et al., 2014). Estimativas locais e globais de biodiversidade demonstram que o encolhimento de um habitat reduz a sua biodiversidade (Wilson, 1999, p. 406).

Segundo o modelo de biogeografia de ilhas, quando um habitat é fragmentado, a capacidade resultante de suporte à biodiversidade depende da área de cada fragmento e não da soma das áreas dos fragmentos resultantes (Macarthur \& Wilson, 1967). Isso ocorre porque há um gradiente ecológico entre a borda de 
cada fragmento e o seu interior, onde as condições ecológicas são mais adequadas para a sobrevivência da biota. Trata-se do "efeito de borda" (Figura 1). 0 crescimento das faixas de borda associado à redução do tamanho das áreas centrais (core) podem inviabilizar determinadas espécies, levando-as à extinção local (Primack \& Rodrigues, 2001). Assim, para a preservação da biodiversidade, é preferível uma paisagem menos fragmentada, com fragmentos naturais maiores.

(a)

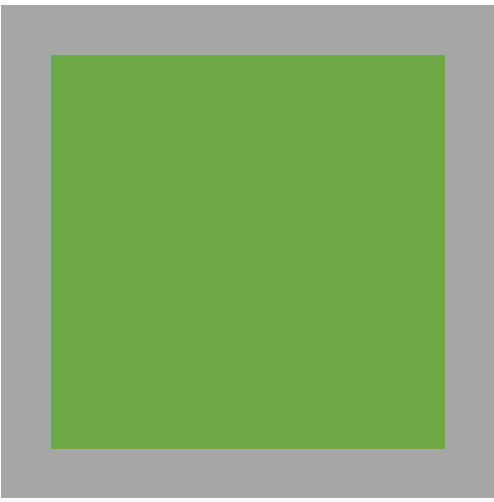

(b)

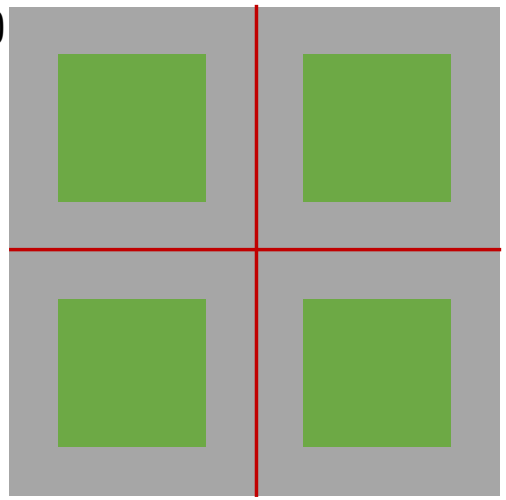

Figura 1 - Representação esquemática da fragmentação de habitat e do efeito de borda em dois momentos: inicial (a) e após a sua fragmentação (b). Legenda: habitat natural em verde, efeito de borda em cinza, elemento fragmentador em vermelho. Fonte: Primack \& Rodrigues, 2001.

O espraiamento é a expansão urbana distanciada do centro, mas que permanece dependente dele. A baixa densidade populacional e a necessidade de usar intensivamente o automóvel individual para a mobilidade urbana são algumas características dessa expansão (Ribeiro \& Silveira, 2009; Ross, 2014; Speck, 2012). O espraiamento urbano é frequentemente estudado em contraposição ao crescimento urbano tradicional, denso e compacto (Ribeiro \& Silveira, 2009; Ross, 2014; Speck, 2012) (Figura 2).

(a)

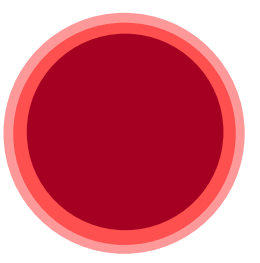

(b)

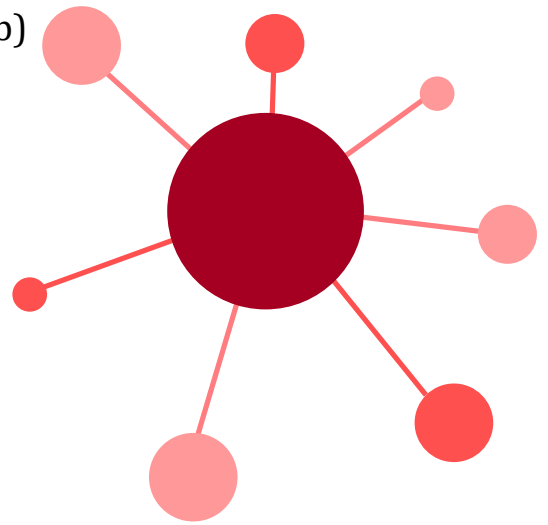

Figura 2 - Dois modelos de expansão urbana: o tradicional (a) e o espraiamento (b). Legenda: gradiente em tons de vermelho onde o tom mais escuro representa alta densidade populacional e o mais claro representa baixa densidade populacional. Fonte: Elaboração dos autores.

Speck (2012) aponta três características desejáveis dos bairros tradicionais: usos mistos, população diversificada e adequação para os deslocamentos a pé. De acordo com o autor, o espraiamento urbano tem cinco componentes: i) parcelamentos residenciais (casas cercadas por estacionamentos), ii) shopping centers (lojas cercadas por estacionamentos), iii) parques comerciais (escritórios cercados por estacionamentos); iv) instituições cívicas (prefeituras, igrejas, escolas, teatros, etc. cercados por estacionamentos); e v) estradas longas conectando os demais componentes (Speck, 2012).

A densidade populacional urbana - razão entre a população total urbana e a área total urbana - é o tema central do urbanismo sustentável, pois o adensamento populacional urbano reduz o consumo per capita de recursos naturais. A título de ilustração, o adensamento reduz o uso do automóvel individual. Consequentemente, ocorrem reduções do consumo energético, da emissão de gases poluentes, das áreas 
destinadas a estacionamentos e da extração das matérias primas necessárias para produzir uma frota crescente de automóveis (Farr, 2013).

No contexto internacional, já há vários estudos que avaliam as repercussões do espraiamento urbano para a fragmentação da paisagem natural. Dupras et al. (2016) analisaram os impactos ecológicos do espraiamento urbano da região metropolitana de Montreal. Eles concluíram que o espraiamento urbano agravou a fragmentação da paisagem natural, reduzindo a sua biodiversidade (Dupras et al., 2016). Terando et al. (2014) fizeram uma projeção de crescimento urbano para o sudeste norte-americano usando o modelo SLEUTH (business-as-usual). Os resultados da pesquisa indicam que, mantendo-se a tendência histórica de espraiamento, a urbanização fragmentará e reduzirá ainda mais as áreas florestais remanescentes (Terando et al, 2014). Geschke et al. (2018), em estudo de caso sobre Melbourne, compararam duas estratégias de desenvolvimento urbano para a conservação da biodiversidade: as cidades compactas (land sparing) e o espraiamento suburbano (land sharing). Os cenários construídos pelos pesquisadores mostram que a cidade compacta (land sparing) é o modelo que mais se aproxima do ideal e que, quanto maior o crescimento populacional, maior é essa aproximação (Geschke et al., 2018).

A ocupação territorial do DF antes da construção de Brasília espelhava o que acontecia no Centro-Oeste brasileiro como um todo: "grandes latifúndios de pecuária extensiva, lavouras de subsistência (arroz, feijão e milho), indústrias de couros, peles, alimentos, calçados e pequenos núcleos urbanos: a cidade de Planaltina e a Vila de Brazlândia" (Ferreira, 2010, p. 45). Em 1955, Juscelino Kubitschek foi eleito presidente. Como parte de sua proposta de governo, estava a construção de Brasília. O projeto de Lucio Costa (1902-1998) para a cidade foi o vencedor do Concurso Nacional do Plano Piloto de Brasília, ocorrido entre setembro de 1956 e março de 1957. As obras para a construção da cidade, iniciadas antes mesmo da definição do certame, continuaram de acordo com as diretrizes do projeto vencedor e Brasília foi inaugurada em 21 de abril de 1960 como "epítome da modernização nacional” (Wisnik, 2010, p. 9).

As cidades-satélites de Brasília surgiram para substituir os acampamentos que abrigavam os operários da construção da cidade. Esses acampamentos, inicialmente, seriam temporários e deveriam ser desmontados antes da inauguração da cidade. Contudo, vários movimentos populares reivindicaram a permanência desses acampamentos ainda na fase de construção da cidade. Assim, algumas cidades-satélites foram planejadas e construídas para receber a população proveniente de assentamentos irregulares próximos ao Plano Piloto e outras cidades-satélites surgiam pela regularização de acampamentos que, inicialmente, seriam temporários (Holston, 1993, p. 257-288).

Brasília cresceu de forma fragmentada, com baixa densidade populacional e em direção a áreas distantes do centro (Plano Piloto) (Vasconcelos, 2010, p. 402-407; Holanda, 2001; Ojima, 2007), enquadrando-se no conceito de cidade espraiada (Ribeiro \& Silveira, 2009; Ross, 2014; Speck, 2012). As cidades-satélites do DF - atualmente denominadas Regiões Administrativas - ilustram isso. Apesar de distantes do Plano Piloto, muitos habitantes delas deslocam-se diariamente para esse centro para trabalhar, estudar, consumir, buscar serviços diversos etc. A literatura científica sobre os efeitos negativos da segregação socioespacial de Brasília é vasta (Epstein, 1973; Holanda, 2001, 2010, 2020; Holston, 1993; Paviani, 2010). Contudo, ainda são escassos os estudos que avaliam o impacto do seu urbanismo para a paisagem natural que precede e envolve a cidade. Este estudo contribui para o melhor entendimento dessa relação ainda pouco explorada. A ecologia de paisagens estuda, além de outras questões, os efeitos negativos da fragmentação da paisagem para os humanos e para a biota. 0 urbanismo estuda, além de outras questões, os efeitos negativos do espraiamento urbano para os humanos e para o ambiente natural. Em ambos os casos, a fragmentação é vista como problemática. Nesta pesquisa, a paisagem em estudo é o mosaico composto pelo meio ambiente natural (Cerrado) e pelo meio ambiente urbano (Brasília). A análise da paisagem desta pesquisa é ilustrada pela sobreposição do cartograma das áreas urbanas ao cartograma da paisagem natural e a subsequente análise dos fragmentos remanescentes de paisagem natural (Figura 3). 
(a.1)

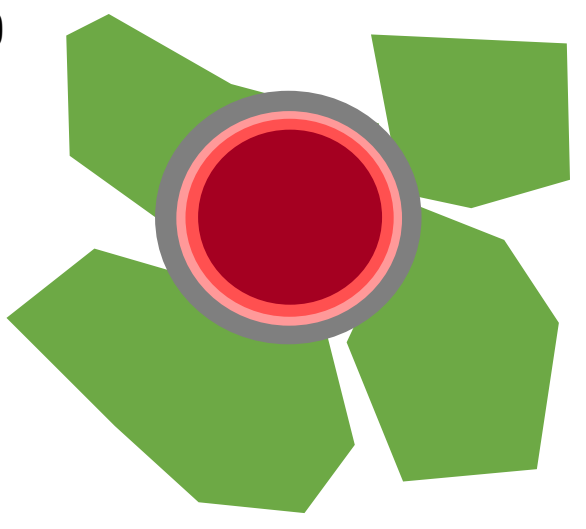

(a.2)

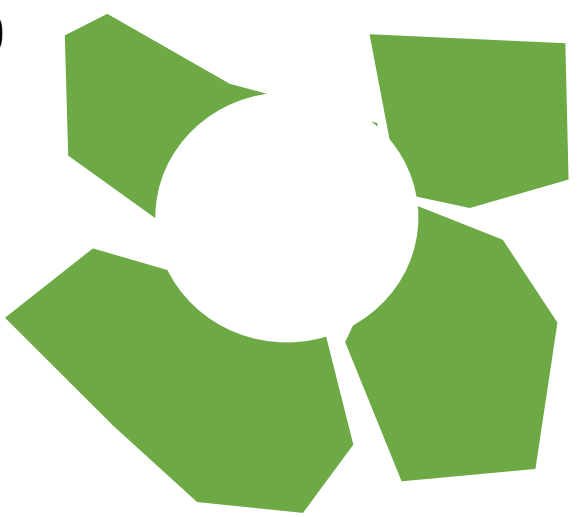

(b.1)

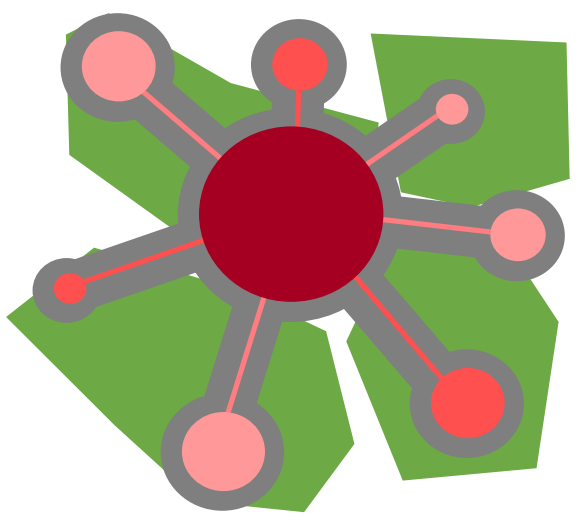

(b.2)

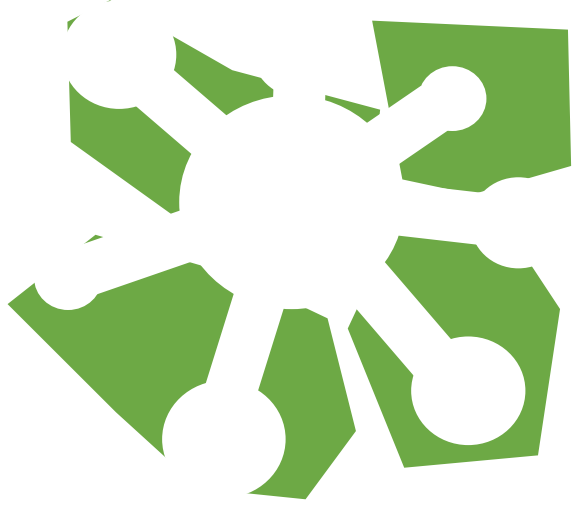

Figura 3 - Esquema cartográfico de análise da paisagem adotada nesta pesquisa. Comparação entre paisagens: o crescimento urbano tradicional (a.1) e a fragmentação resultante desse crescimento (a.2); espraiamento urbano (b.1) e a fragmentação resultante desse crescimento (b.2). Fonte: Elaboração dos autores.

\section{Métodos}

\section{Análise diacrônica}

A análise diacrônica desta pesquisa avaliou as transformações da paisagem do DF entre 1953-2013. Mapeamentos realizados por outros estudos permitiram selecionar os seguintes anos para a análise: 1953, 1964, 1973, 1984, 1994, 1998, 2001 e 2013.

O estudo Vegetação do Distrito Federal: tempo e espaço (Unesco, 2002) foi a principal fonte de dados para a análise diacrônica, pois reuniu mapeamentos de uso do solo e de vegetação do DF entre 1953 (momento anterior à construção da cidade) e 2001. O mapeamento do projeto TerraClass Cerrado 2013 (Brasil, 2015) forneceu dados referentes ao ano de 2013.

Para fins deste estudo, o tratamento dos dados - realizado no programa ArcMap 10.3.1 - resultou na reclassificação das paisagens em seis categorias de uso do solo: agricultura, paisagem natural, área urbana, reflorestamento, corpos d'água e solo exposto (Figura 4). Em seguida, foi feito o cálculo de quatro métricas de cada paisagem reclassificada: i) número de fragmentos (NumP), ii) tamanho médio de fragmentos (MPS), iii) área total da classe (CA), e iv) comprimento total do perímetro/borda de cada classe (TE). 0 cálculo foi feito com o plugin Patch Analyst rodado no programa ArcMap 10.3.1.

As diferenças metodológicas entre o estudo da Unesco e o TerraClass podem distorcer os resultados desta análise. Por isso, adotou-se um padrão tracejado de linha nos gráficos para o último período da análise diacrônica (2001-2013). 

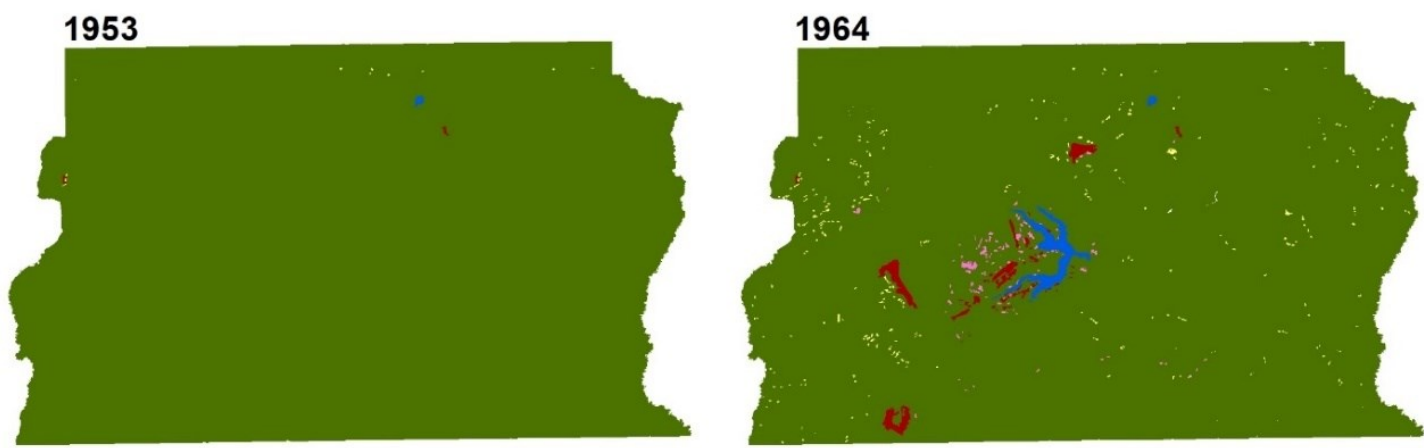

\section{3}

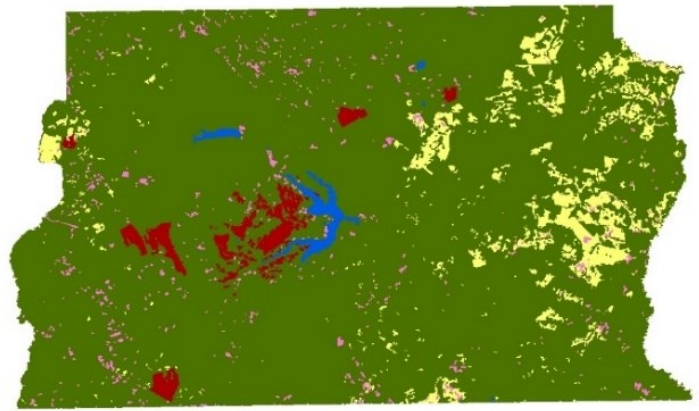

\section{4}

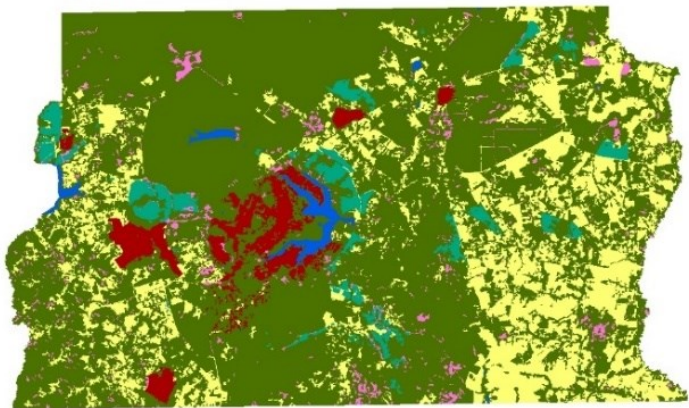

1994

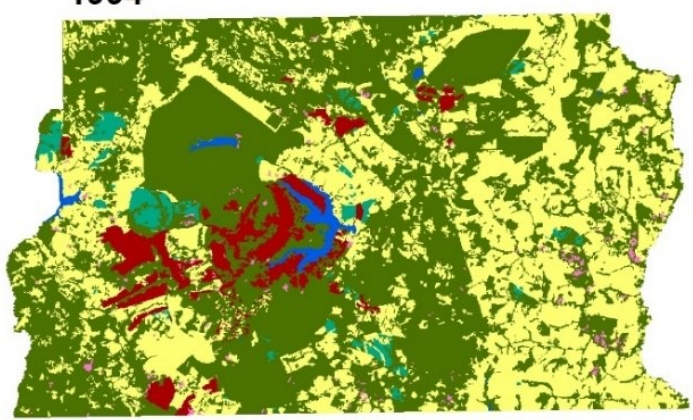

\section{8}

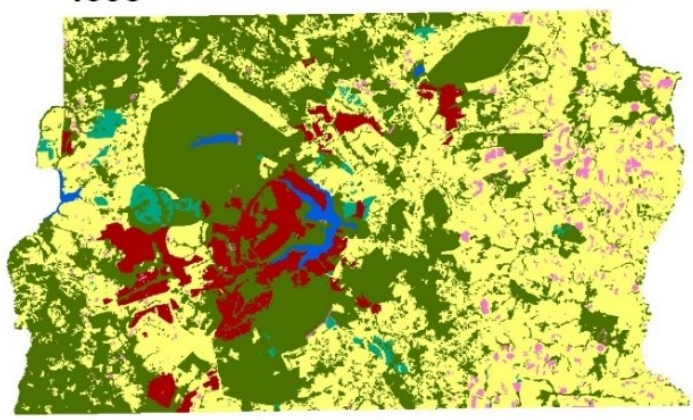

\section{1}
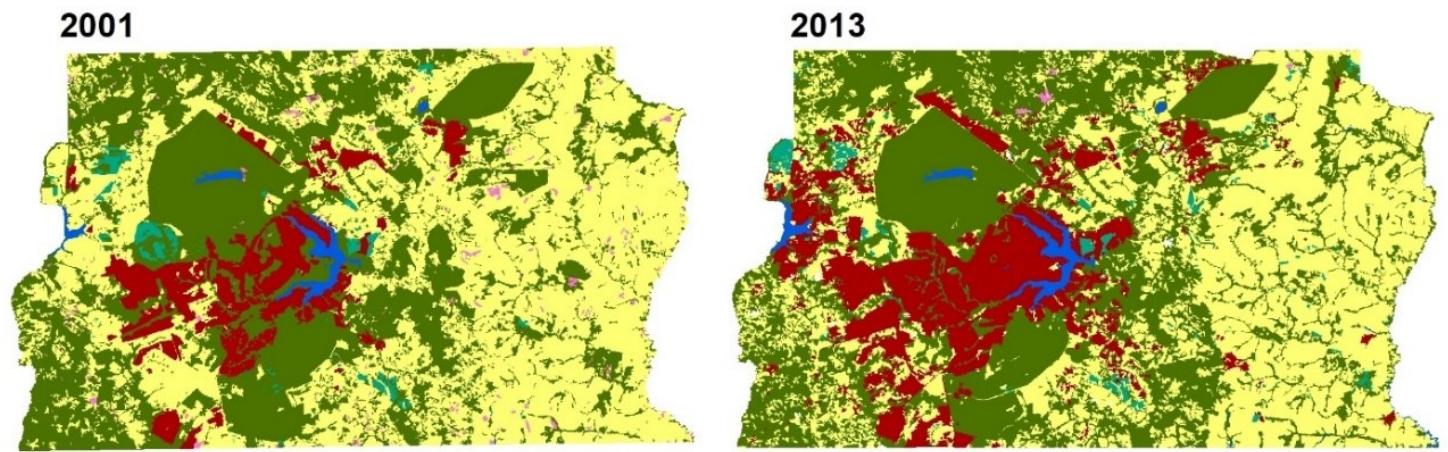

Figura 4 - Evolução da paisagem do Distrito Federal, 1953-2013. Legenda: agricultura em amarelo, paisagem natural em verde escuro, área urbana em vermelho, reflorestamento em verde claro, corpos d'água em azul e solo exposto em rosa. Elaboração dos autores. Fontes: UNESCO (2002) e BRASIL (2015).

Análise sincrônica

A análise sincrônica comparou a distribuição das densidades populacionais urbanas das metrópoles brasileiras em 2015. Com base em estudos do IBGE, selecionamos as metrópoles analisadas e calculamos as densidades populacionais urbanas de cada município de cada metrópole. Como o DF não possui municípios, usamos o subdistrito censitário como recorte espacial para o cálculo das densidades de Brasília. Consideramos apenas as áreas efetivamente urbanizadas de cada metrópole para um cálculo preciso da densidade populacional urbana. 
Usamos o estudo Arranjos populacionais e concentrações urbanas no Brasil (IBGE, 2016) para identificar as concentrações urbanas brasileiras de caráter metropolitano (com mais de 2.500 .000 habitantes), a saber: São Paulo/SP, Rio de Janeiro/RJ, Belo Horizonte/MG, Recife/PE, Porto Alegre/RS, Salvador/BA, Brasília/DF, Fortaleza/CE e Curitiba/PR (IBGE, 2016, p. 52). Usamos os arquivos vetoriais das áreas urbanizadas de cada concentração urbana do estudo Áreas urbanizadas do Brasil: 2015 (IBGE, 2017). Usamos os dados demográficos do Censo de 2010 referentes à população urbana (IBGE, 2012) para estimar as densidades populacionais urbanas em 2015

\section{Resultados}

\section{Análise diacrônica}

Os resultados do número de fragmentos (NumP) (Quadro 1 e Figura 5) mostram que em 1953 havia no DF apenas dois fragmentos urbanos (Brazlândia e Planaltina), onze fragmentos agrícolas e uma área de paisagem natural do Cerrado. Com o tempo, cresceu o número de fragmentos de todas as classes, consequência esperada da fragmentação. A queda brusca no número de fragmentos agrícolas entre 19941998 parece indicar a fusão de fragmentos pequenos e a formação de fragmentos maiores. 0 expressivo crescimento do tamanho médio dos fragmentos (MPS) agrícolas no mesmo período corrobora essa interpretação (Figura 7). A queda acentuada no número de fragmentos naturais associada ao crescimento acentuado de fragmentos agrícolas entre 2001-2013 parece decorrer de divergências classificatórias entre os dois mapeamentos usados.

Quadro 1 - Resultado do cálculo das métricas de paisagem para o Distrito Federal, 1953-2013.

\begin{tabular}{|c|c|c|c|c|c|c|c|c|c|}
\hline \multicolumn{5}{|c|}{1953} & \multicolumn{5}{|c|}{1964} \\
\hline classe & NumP & MPS $\left(\mathrm{km}^{2}\right)$ & TE (km) & $\mathrm{CA}\left(\mathrm{km}^{2}\right)$ & classe & NumP & MPS $\left(\mathrm{km}^{2}\right)$ & TE (km) & $\mathrm{CA}\left(\mathrm{km}^{2}\right)$ \\
\hline natural & 1 & $5.784,50$ & 447,21 & $5.784,50$ & natural & 11 & 514,41 & $1.349,82$ & $5.658,47$ \\
\hline urbana & 2 & 0,60 & 8,93 & 1,21 & urbana & 47 & 0,98 & 220,87 & 46,25 \\
\hline & 11 & 0,08 & 14,61 & 0,93 & rícola & 290 & 0,09 & 387,95 & 25,70 \\
\hline \multicolumn{5}{|c|}{1973} & \multicolumn{5}{|c|}{1984} \\
\hline classe & NumP & MPS $\left(\mathrm{km}^{2}\right)$ & TE (km) & $\mathrm{CA}\left(\mathrm{km}^{2}\right)$ & CIusoe & NumP & MPS $\left(\mathrm{km}^{2}\right)$ & TE (km) & $\mathrm{CA}\left(\mathrm{km}^{2}\right)$ \\
\hline natural & 91 & 56,99 & $4.065,51$ & $5.186,17$ & natural & 508 & 7,84 & $11.929,84$ & $3.983,43$ \\
\hline urbana & 46 & 2,66 & 430,96 & 122,42 & urbana & 110 & 1,95 & 988,97 & 214,09 \\
\hline & 439 & 0,74 & $2.107,88$ & 324,89 & ola & 657 & 1,84 & $8.068,28$ & $1.209,54$ \\
\hline \multicolumn{5}{|c|}{1994} & \multicolumn{5}{|c|}{1998} \\
\hline classe & Num & MPS $\left(\mathrm{km}^{2}\right)$ & $\mathrm{TE}(\mathrm{km})$ & CA & Cin & NumP & MPS $\left(\mathrm{km}^{2}\right)$ & TE (l & $\mathrm{CA}\left(\mathrm{km}^{2}\right)$ \\
\hline natural & 529 & 5,96 & $11.473,67$ & $3.150,22$ & natural & 1.192 & 2,04 & $10.609,48$ & $2.433,92$ \\
\hline urbana & 137 & 2,05 & $1.113,46$ & 281,34 & urbana & 48 & 7,95 & $1.069,49$ & 381,79 \\
\hline & 874 & 2,45 & $10.209,86$ & $2.138,96$ & cola & 402 & 6,70 & $11.213,10$ & $2.693,66$ \\
\hline \multicolumn{5}{|c|}{2001} & \multicolumn{5}{|c|}{2013} \\
\hline cla & NumP & MPS $\left(\mathrm{km}^{2}\right)$ & TE (km) & $\mathrm{CA}\left(\mathrm{km}^{2}\right)$ & & NumP & MPS $\left(\mathrm{km}^{2}\right)$ & TE (km) & $\mathrm{CA}\left(\mathrm{km}^{2}\right)$ \\
\hline & 1.200 & 2,03 & $10.780,40$ & $2.432,95$ & natural & 547 & 4,32 & $10.591,20$ & $2.362,21$ \\
\hline & 58 & 7,41 & $1.196,65$ & 429,84 & urbana & 255 & 3,43 & $3.279,81$ & 873,68 \\
\hline agrícola & 463 & 5,95 & $10.465,49$ & $2.755,84$ & agrícola & 1.085 & 2,19 & $10.610,87$ & $2.379,67$ \\
\hline
\end{tabular}

Fontes: Elaboração dos autores com base em UNESCO (2002) e BRASIL (MMA, 2015). 


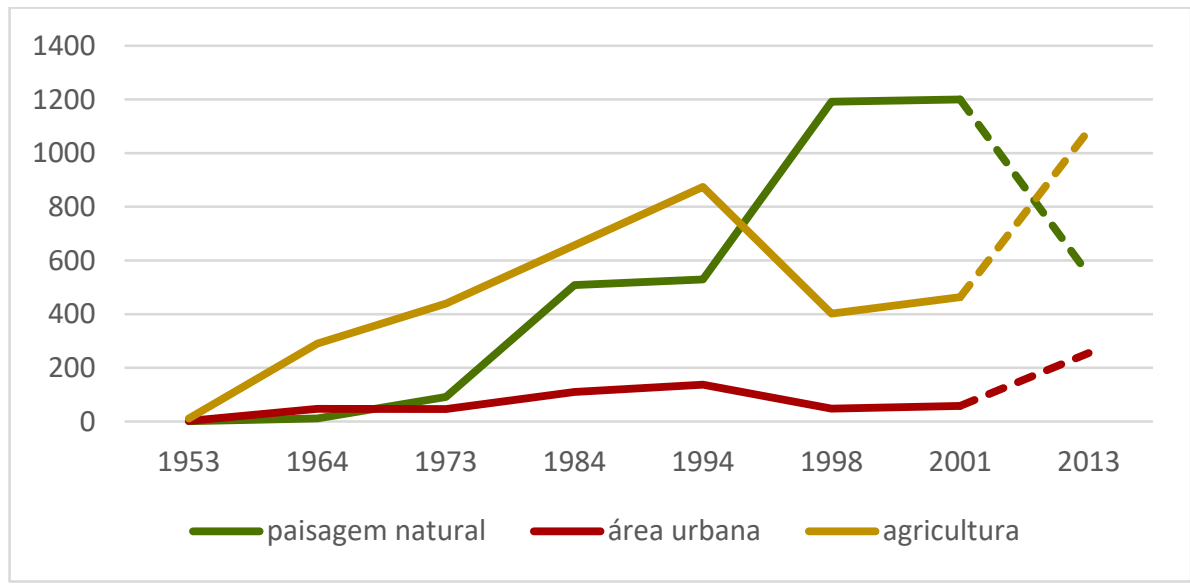

Figura 5 - Evolução do número de fragmentos (NumP) da paisagem do Distrito Federal entre 1953-2013, classes selecionadas. Fonte: Elaborado pelos autores com base nos dados do Quadro 1.

Os resultados do tamanho médio de fragmentos (MPS) (Quadro 1 e Figuras 6 e 7) mostram uma redução expressiva da paisagem natural. Já as áreas urbanas e agrícolas apresentam curvas semelhantes: crescimento até 1998 e redução desde então. 0 tamanho médio dos fragmentos (MPS) da classe natural caiu tão acentuadamente $\left(5.784,50 \mathrm{~km}^{2}\right.$ em 1953 e 4,32 km² em 2013) que foi necessário separar a análise dessa métrica em dois gráficos: um apenas para a classe da paisagem natural (Figura 6) e outro para as áreas urbanas e agrícolas (Figura 7).

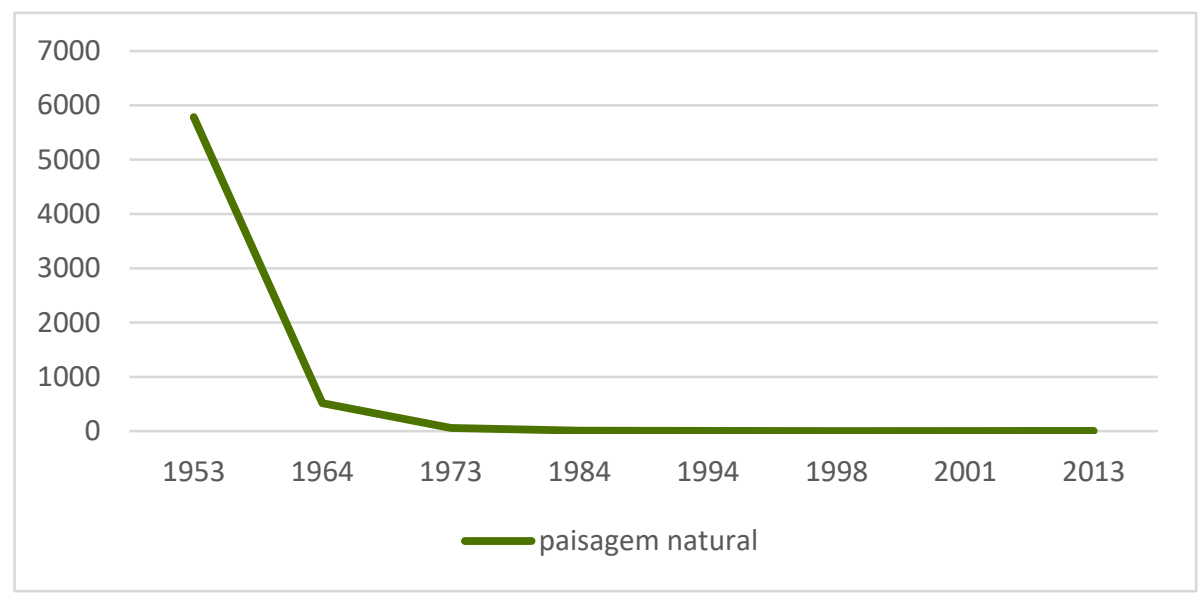

Figura 6 - Evolução do tamanho médio dos fragmentos (MPS), em km², da paisagem do Distrito Federal, 1953-2013, para a paisagem natural. Fonte: Elaborado pelos autores com base nos dados do Quadro 1.

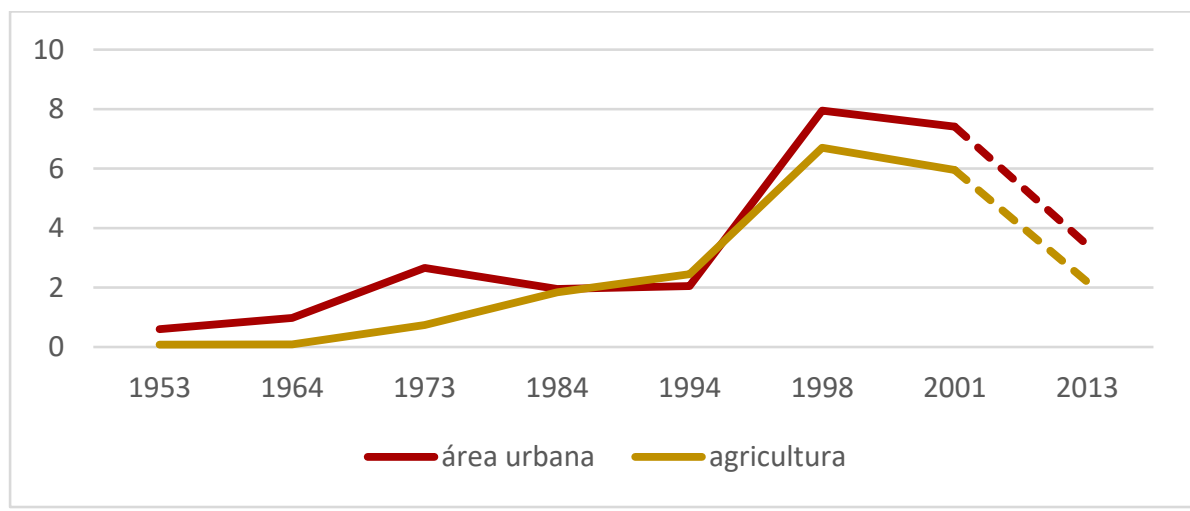

Figura 7 - Evolução do tamanho médio dos fragmentos (MPS), em km², da paisagem do Distrito Federal entre 1953-2013 para as classes: área urbana e agricultura. Fonte: Elaborado pelos autores com base nos dados do Quadro 1. 
Os resultados da área total da classe (CA) (Quadro 1 e Figura 8) mostram uma queda expressiva na área total de paisagem natural. As áreas urbanas seguiram uma tendência constante de crescimento, com uma acentuação da curva no último período da análise (2001-2013). Já as áreas agrícolas seguiram uma tendência de expansão até 2001 e de leve retração entre 2001-2013. Tanto o aumento acentuado da área urbana quanto a retração das áreas agrícolas entre 2001-2013 parecem refletir uma divergência de classificação entre os mapeamentos usados.

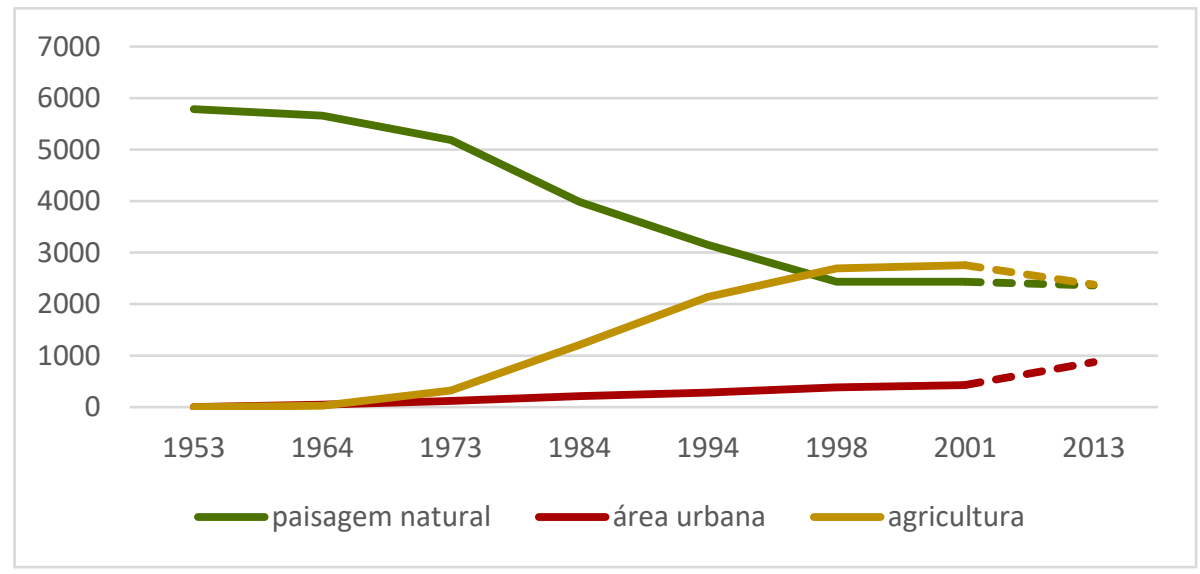

Figura 8 - Evolução da área total da classe (CA), em km², da paisagem do Distrito Federal entre 1953-2013 para as seguintes classes: paisagem natural, área urbana e agricultura. Fonte: Elaborado pelos autores com base nos dados do Quadro 1.

Os resultados do comprimento total do perímetro/borda para cada classe (TE) (Quadro 1 e Figura 9) mostram uma tendência de crescimento do comprimento total da borda para as três classes. Para a classe da paisagem natural, cuja área total (CA) caiu significativamente (Figura 8), o crescimento no comprimento total das bordas indica fragmentação. A inclinação acentuada na curva das áreas urbanas entre 2001 e 2013 deve decorrer da divergência metodológica entre os dois mapeamentos.

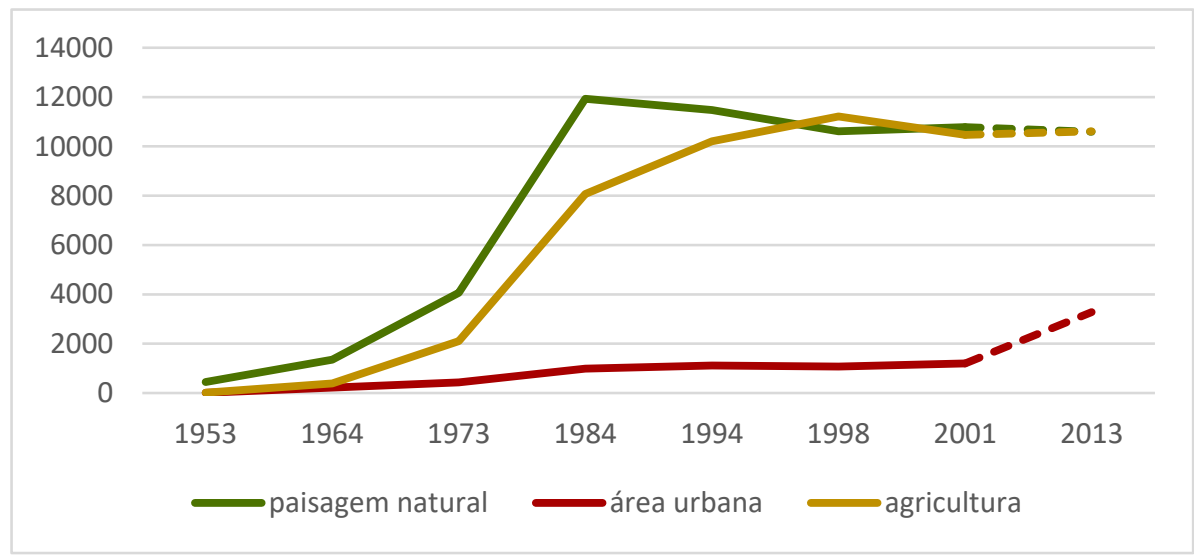

Figura 9 - Evolução do comprimento total da borda para cada classe (TE), em km, da paisagem do Distrito Federal, 1953-2013, para as seguintes classes: paisagem natural, área urbana e agricultura. Fonte: Elaborado pelos autores com base nos dados do Quadro 1.

\section{Análise sincrônica}

A distribuição das densidades populacionais urbanas nas concentrações urbanas brasileiras de caráter metropolitano para 2015 (Figura 10) mostra que, geralmente, o centro da concentração urbana é a região mais densa e as áreas periféricas são as menos densas. A única exceção é a concentração urbana de Brasília. O seu centro é a Região Administrativa de Brasília (RA I) - uma das densidades populacionais urbanas mais baixas (2.865 hab $/ \mathrm{km}^{2}$ ), superior apenas às Regiões do Lago Sul, Núcleo Bandeirante (por conta do Park Way, bairro exclusivamente residencial com lotes unifamiliares variando de $2.500 \mathrm{~m}^{2}$ a $20.000 \mathrm{~m}^{2}$ ) e Lago 
Norte. As três regiões administrativas com densidades muito altas (acima de $10.000 \mathrm{hab} / \mathrm{km}^{2}$ ) encontramse afastadas do centro e são elas: Ceilândia, Recanto das Emas e Candangolândia.
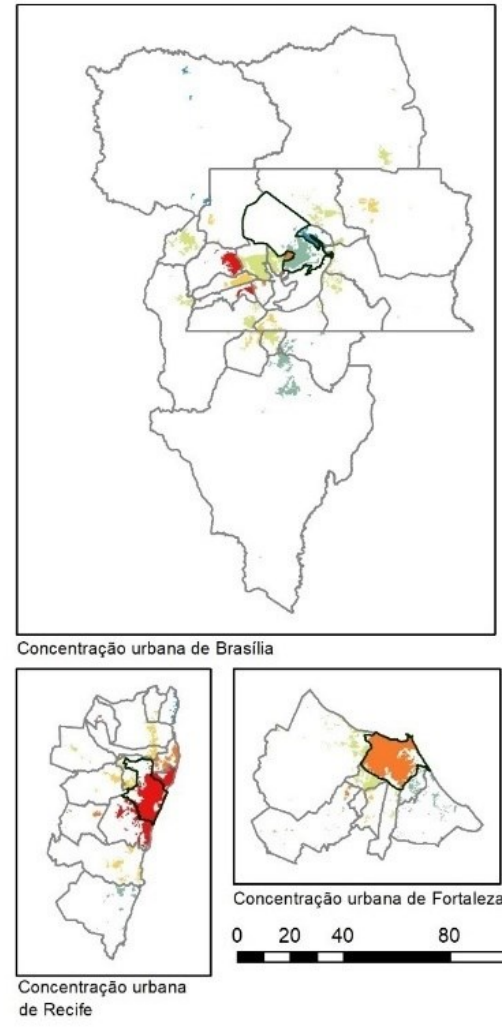

80
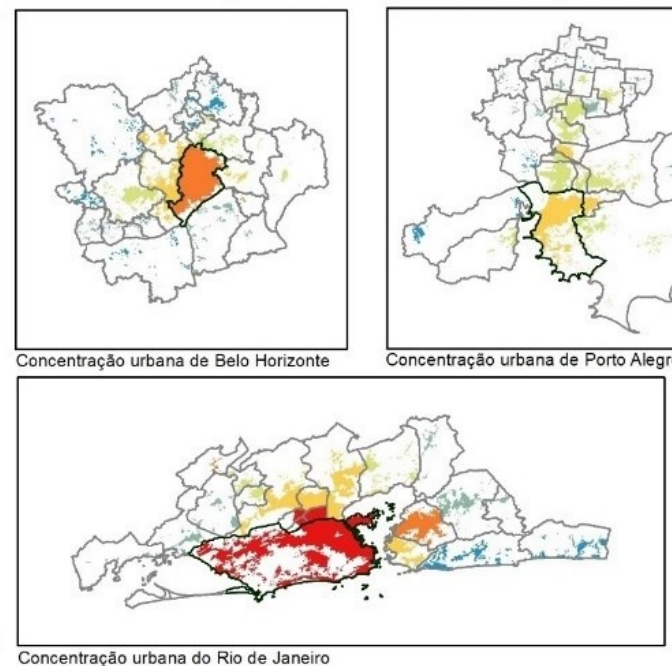

Concentração urbana do Rio de Janeiro
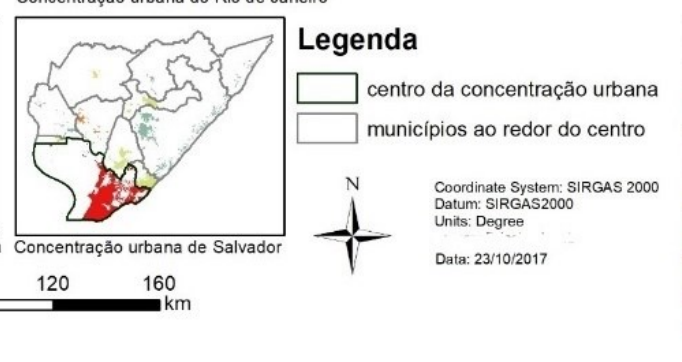

\section{,}
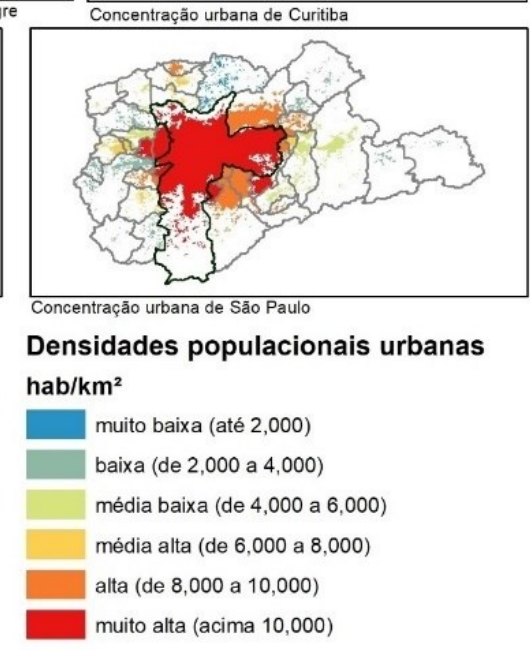

Densidades populacionais urbanas $\mathrm{b} / \mathrm{km}^{2}$

Figura 10 - Distribuição das densidades populacionais urbanas dentro das concentrações urbanas brasileiras de caráter metropolitano, 2015. Fontes: Elaborada pelos autores com base em IBGE (2012), IBGE (2016) e IBGE (2017).

Além da inversão na distribuição da densidade populacional urbana, Brasília apresenta a menor densidade populacional urbana média (Quadro 2 e Figura 11). Ou seja, no contexto brasileiro, a concentração urbana de Brasília é a que tem menos habitantes por unidade de área urbanizada. A densidade populacional urbana de Brasília (4.729 hab/ $\mathrm{km}^{2}$ ) é aproximadamente metade da calculada para Salvador/BA (9.701 hab $\left./ \mathrm{km}^{2}\right)$ - a mais alta de todas.

Quadro 2 - Densidades populacionais das concentrações urbanas em análise, 2010-2014.

\begin{tabular}{|c|c|c|c|c|}
\hline $\begin{array}{l}\text { Concentração } \\
\text { urbana }\end{array}$ & $\begin{array}{l}\text { Número de } \\
\text { municípios }\end{array}$ & $\begin{array}{l}\text { concentrações urban } \\
\text { População urbana } \\
\text { (hab) } 2010\end{array}$ & $\begin{array}{l}\text { s } 2010-2014 \\
\text { Área urbana } \\
\left(\mathrm{km}^{2}\right) 2011-2014\end{array}$ & $\begin{array}{l}\text { Densidade populacional } \\
\text { urbana (hab//km²) }\end{array}$ \\
\hline São Paulo & 37 & 19.243 .982 & $2.014,65$ & 9.552 \\
\hline Rio de Janeiro & 21 & 11.868 .969 & $1.503,45$ & 7.894 \\
\hline Belo Horizonte & 23 & 4.653 .182 & 781,31 & 5.956 \\
\hline Recife & 15 & 3.612 .985 & 401,42 & 9.001 \\
\hline Porto Alegre & 29 & 3.550 .747 & 680,72 & 5.216 \\
\hline Salvador & 10 & 3.423 .641 & 352,93 & 9.701 \\
\hline Brasilia & 9 & 3.222 .184 & 681,30 & 4.729 \\
\hline Fortaleza & 8 & 3.192 .230 & 401,77 & 7.945 \\
\hline Curitiba & 18 & 2.843 .616 & 583,40 & 4.874 \\
\hline
\end{tabular}

Fontes: Elaborado pelos autores com base em Censo 2010, IBGE, 2016 e IBGE, 2017. 


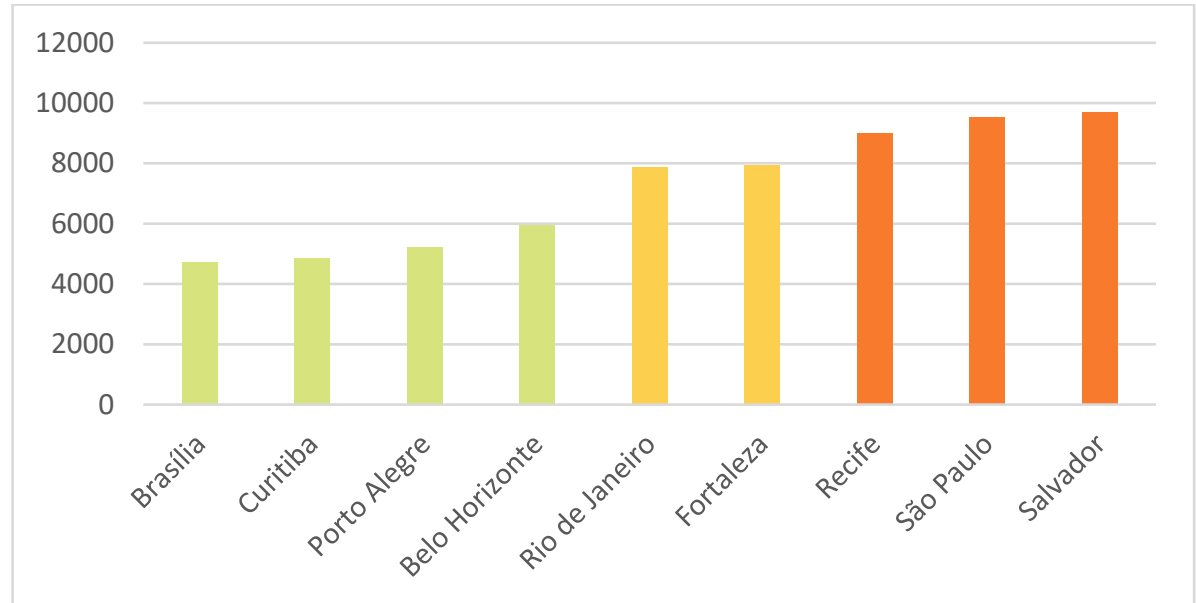

Figura 11 - Densidades populacionais urbanas médias das concentrações urbanas analisadas, 2010-2014. Fonte: Elaborado pelos autores com base nos dados do Quadro 2.

Embora o Censo de 2010 (IBGE, 2012) possibilite comparar várias concentrações urbanas brasileiras, os seus dados populacionais agrupam áreas com densidades populacionais urbanas distintas num único subdistrito censitário. Para uma análise mais precisa da distribuição da densidade populacional urbana de Brasília, objeto desta pesquisa, as densidades foram recalculadas por região administrativa com base nos dados da Pesquisa Distrital por Amostra de Domicílios (PDAD) para o ano de 2011 (Codeplan, 2012) (Figura 12). 


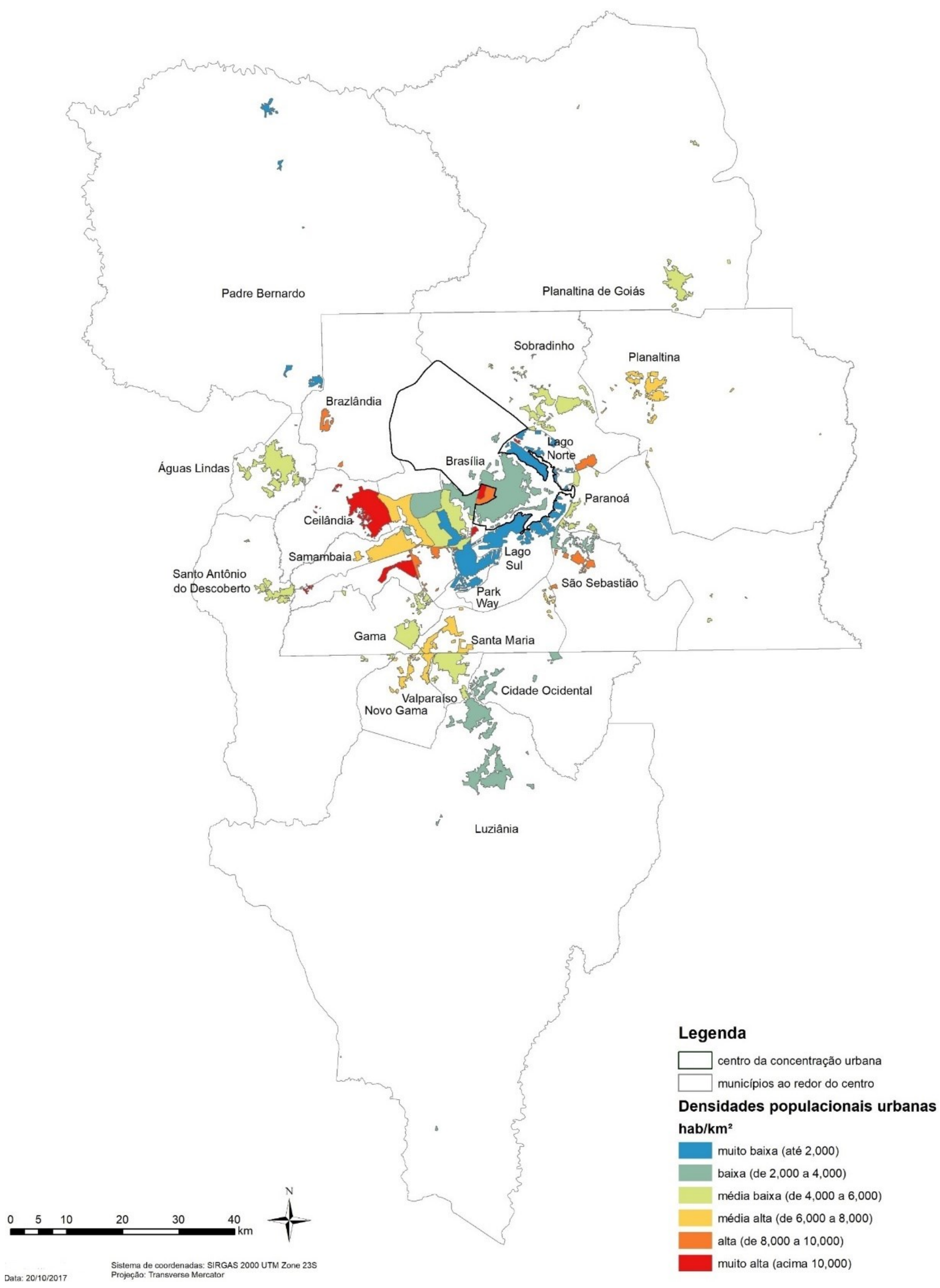

Figura 12 - Distribuição geográfica das densidades populacionais urbanas na concentração urbana de Brasília, 2011 .Elaborada pelos autores. Fontes: Censo de 2010 para os municípios goianos e Pesquisa Distrital por Amostra de Domicílios (PDAD) de 2011 para o DF. 
O cenário hipotético (Figura 13) de crescimento urbano tradicional para Brasília seguiu os seguintes parâmetros: i) densidade populacional urbana média das concentrações urbanas estudadas na análise sincrônica (aproximadamente $7.200 \mathrm{hab} / \mathrm{km}^{2}$ ); e ii) crescimento urbano contíguo ao centro. 0 cenário mostra que os 3.293.877 habitantes da concentração urbana de Brasília (2011) caberiam numa área de aproximadamente $457 \mathrm{~km}^{2}$. Em relação à cidade real (Figura 12), de $684 \mathrm{~km}^{2}$, o cenário hipotético indica uma redução de $227 \mathrm{~km}^{2}$ (33\%) na área urbanizada.

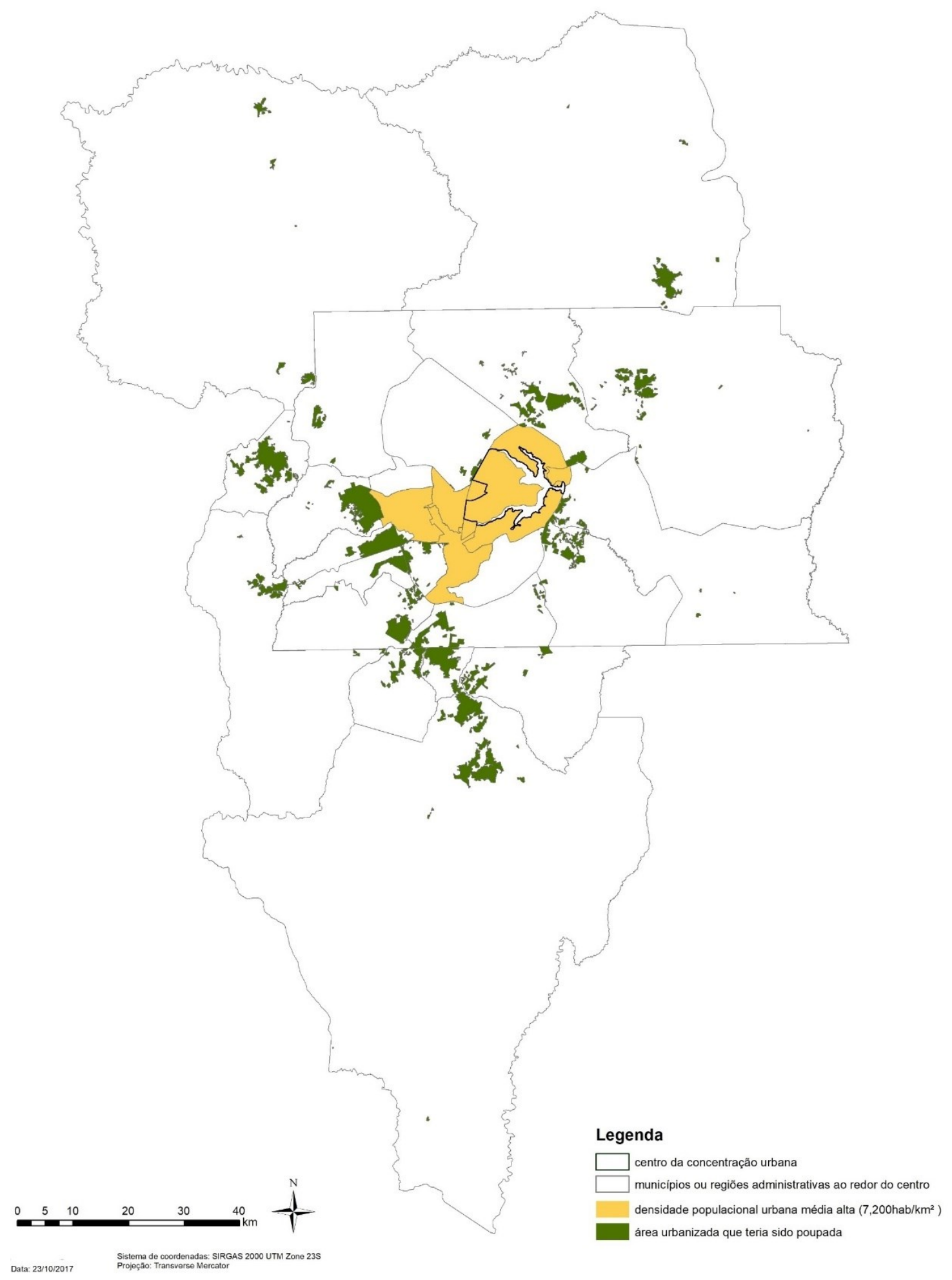

Figura 13. Cenário hipotético de Brasília, 2011, caso o seu modelo de crescimento urbano tivesse sido compacto e com a densidade média das concentrações urbanas brasileiras de caráter metropolitano. Fonte: Elaborado pelos autores. Adaptação com base na Figura 12. 
Não se deve confundir esse cenário hipotético com uma paisagem do tipo "selva de concreto" e de excessivo adensamento humano. Trata-se de uma média das densidades populacionais urbanas existentes no Brasil. No contexto internacional, há cidades mais densas. Por exemplo, em 2014, Paris tinha uma densidade de $21.066,8 \mathrm{hab} / \mathrm{km}^{2}$, ou seja, quase três vezes superior à densidade calculada para o cenário. ${ }^{1}$

\section{Discussão}

Os resultados apontam que, sob a perspectiva da conservação da biodiversidade do Cerrado, o crescimento urbano de Brasília deve favorecer o adensamento populacional e a compactação da cidade. $\mathrm{O}$ adensamento urbano, ao intensificar o uso do solo, evita a expansão territorial desnecessária da cidade. A compactação, ao localizar a expansão territorial da cidade em áreas centrais disponíveis, reduz a fragmentação urbana.

Muitas vezes confundida com a verticalização, a densidade populacional urbana depende de outras variáveis relevantes: tamanho dos imóveis, áreas não construídas, número de habitantes por domicílio e número de habitações desocupadas. A mera observação da verticalização não é suficiente para chegar a conclusões acerca da densidade populacional urbana (Castro, 2019). Águas Claras, área notadamente verticalizada em Brasília, tem densidade média baixa (5.599 hab $\left./ \mathrm{km}^{2}\right)$. Já a Candangolândia, área notadamente horizontalizada, tem densidade muito alta $\left(11.709 \mathrm{hab} / \mathrm{km}^{2}\right)$.

Os resultados indicam que Brasília não é uma cidade excessivamente densa nem populosa. No contexto brasileiro, Brasília é a concentração urbana de caráter metropolitano menos densa e a terceira menos populosa (Quadro 2 e Figura 11). Contudo, ainda persiste a noção de que Brasília cresceu mais do que deveria. Três parâmetros equivocadamente interpretados contribuem para essa noção: i) a ideia de que Brasília não deveria ter superado 500.000 habitantes; ii) a grande quantidade de carros e o tamanho dos engarrafamentos; e iii) comparações baseadas nas densidades demográficas das 27 Unidades Federativas (UFs) brasileiras.

Quanto ao limite de 500.000 habitantes, ele não constava do edital para o concurso do projeto do Plano Piloto nem do projeto vencedor. Em 16 de outubro de 1956, o Instituto de Arquitetos do Brasil (IAB) enviou uma correspondência à Companhia Urbanizadora da Nova Capital do Brasil (Novacap) solicitando maiores esclarecimentos acerca do Edital do Concurso Nacional do Plano Piloto da Nova Capital do Brasil. A resposta, assinada por Oscar Niemeyer (1907-2012) — então Diretor do Departamento de Urbanismo e Arquitetura da Novacap - estipulou o limite de 500 mil habitantes (Braga, 2010, p. 42-43). Esse número referia-se apenas ao projeto do Plano Piloto. De acordo com a PDAD 2011, em 2010 a população do Plano Piloto somada à do Lago Norte e à do Lago Sul - áreas que compunham o projeto original de Lucio Costa (Costa, 1957) - era de 273.129 habitantes, aproximadamente 55\% do limite de 500.000 habitantes. Cabe, ainda, avaliar se é razoável e viável limitar o tamanho populacional de uma cidade. Entendemos que não. A imposição de um limite populacional a uma cidade pode levar a atitudes autoritárias e socialmente excludentes. Afinal, quais seriam os critérios para obtenção de um visto de residência nessa cidade?

Quanto aos problemas decorrentes do excesso de automóveis em Brasília, eles podem ser consequência da forma espraiada da cidade e não do número de habitantes. Cidades espraiadas dificultam os deslocamentos a pé e por transporte público e fazem com que o uso do automóvel individual seja a melhor opção. O cenário hipotético de adensamento e compactação (Figura 13) proporcionaria o contrário: facilitaria os deslocamentos a pé e por transporte público, tornando menos necessário o uso do automóvel individual (Farr, 2013; Ross, 2014; Speck, 2012). Assim, estudos de impacto de vizinhança e projeções futuras de fluxo de automóveis para novos projetos de urbanização devem considerar que o adensamento populacional e a compactação morfológica da cidade não implicam, necessariamente, um crescimento linear do número de automóveis. Ao contrário, como uma parábola invertida, ao se alcançar um patamar mínimo

\footnotetext{
${ }^{1}$ Fonte: Institut National de la Statistique et des Études Économiques (Insee), órgão responsável por coletar, produzir, analisar e difundir informações sobre a economia e a sociedade francesas. Recuperado em 14 de dezembro de 2017, de https://www.insee.fr/fr/statistiques/1405599?geo=DEP-75
} 
de densidade e compacidade, o automóvel deixa de ser a melhor opção individual para deslocamento na cidade e a sua quantidade, per capita, tende a cair (Koster et al., 2019).

As comparações de densidade populacional das UFs brasileiras são inadequadas para estudos urbanos, pois incluem na análise extensas áreas não urbanas, como as áreas naturais e as agrícolas. 0 DF tem área total muito inferior às dos estados e é a única UF criada com o propósito de abrigar uma cidade. Portanto, quando comparado aos 26 estados brasileiros, é esperado que o DF apresente a maior densidade populacional. Contudo, UF e área urbana são conceitos distintos. Assim, o DF é a UF mais densamente povoada, mas abriga a concentração urbana brasileira de caráter metropolitano menos densa, como os resultados desta pesquisa provam.

Há um debate na comunidade científica acerca de dois modelos de uso do solo e suas implicações para a conservação da biodiversidade: o land sharing e o land sparing. 0 modelo de land sharing preconiza o uso compartilhado do solo. Ele propõe a coexistência, numa mesma área, da exploração humana dos recursos naturais e da conservação da biodiversidade. Já o modelo do land sparing busca preservar as áreas exclusivamente naturais ao intensificar a produção em áreas exclusivamente agrícolas (Waggoner, 1996; Green et al., 2005; Phalan et al., 2011, 2016).

Inicialmente proposto para analisar a relação entre agricultura e preservação ambiental, o debate pode ser ampliado para outras formas de uso do solo - como a urbanização. A urbanização, ainda que rarefeita pelo espraiamento urbano, não significa paisagem natural preservada. A classificação de áreas com densidades muito baixas como urbanas - e não como naturais - pela metodologia do SIG nos estudos da Unesco e do TerraClass (Figura 12) ilustra isso. Além disso, a coexistência dos habitantes urbanos com espécies da biota que lhes apresentem risco gera tensões e se torna praticamente impossível. Assim, entendemos que a melhor opção para a relação cidade-natureza é o land sparing. Uma forma de se alcançar a intensificação do uso urbano do solo seria o adensamento populacional e a compactação espacial da cidade, como no cenário aqui proposto (Figura 13).

As três principais unidades de conservação do DF — o Parque Nacional de Brasília, a Estação Ecológica de Águas Emendadas e Área de Proteção Ambiental (APA) Gama e Cabeça de Veado — abrangem as maiores áreas contínuas de Brasília em que a paisagem natural se manteve preservada. Ou seja, a criação de áreas protegidas, no DF, foi a melhor estratégia de conservação. Se a urbanização com densidades muito baixas tivesse favorecido a conservação da paisagem natural, de acordo com a proposta do land sharing, a interpretação de imagens de satélite, pela metodologia do SIG, teria classificado áreas urbanas pouco densas como naturais e não como urbanas.

Os eventuais remanescentes da biota original nas áreas urbanas com densidade populacional muito baixa não configuram necessariamente uma paisagem natural preservada, onde a biota possa existir livremente. Ainda que os quintais sejam vastos e incluam um exemplar ou outro de vegetação nativa, eles são áreas verdes urbanas privadas, isoladas do resto da paisagem. Muros e cercas são barreiras intransponíveis para certas espécies da biota. Ademais, uma vez urbanizada, a área precisa ser segura para os seres humanos que a habitam. Espécies animais e vegetais que ofereçam algum risco para os seres humanos serão combatidas pela caça, pela captura, pela introdução de espécies exóticas, pela pulverização de substâncias químicas ou por outros métodos de controle biológico destinados à proteção dos seres humanos.

A Nova Agenda Urbana (ONU, 2016), produzida na Terceira Conferência das Nações Unidas sobre Moradia e Desenvolvimento Urbano Sustentável (Habitat III), busca orientar o desenvolvimento urbano das cidades pelos próximos 20 anos. Ela destaca a necessidade de se conter o espraiamento urbano (ONU, 2016, $\S 52, \S 69, \S 97)$ e aponta os benefícios da aglomeração, dos usos mistos, do adensamento populacional e da compacidade urbanos (ONU, 2016, §44, §51, §52 e §69). De acordo com o documento, o espraiamento deve ser combatido tanto para corrigir a segregação socioespacial quanto para preservar áreas naturais. Os resultados desta pesquisa atestam a correção dessas orientações.

Boa parte das terras do DF foram desapropriadas para a construção de Brasília. O Estado poderia ter implantado bairros planejados próximos ao Plano Piloto para atender à demanda urbana crescente — como 
o cenário proposto nesta pesquisa (Figura 13) —, mas não o fez. Ao contrário, a política de expansão da cidade optou por áreas distantes do Plano Piloto, inclusive sob o pretexto de preservação ambiental. No entanto, a urbanização é um processo inevitável de aglomeração humana. Com o tempo, áreas próximas ao Plano Piloto foram urbanizadas de forma planejada (como os setores Sudoeste e Noroeste), mas principalmente de forma não planejada (como a Estrutural, o Varjão etc.). A política inicial de urbanização fragmentada acabou promovendo uma pulverização tão intensa que a cidade extrapolou o DF e invadiu o entorno goiano (Figura 14).

O Estatuto da Cidade, o Zoneamento Ecológico-Econômico (ZEE) e o Plano Diretor (PD) são instrumentos legais para uma melhor gestão das cidades brasileiras. Contudo, é indispensável que os ZEEs e os PDs ofereçam propostas adequadas de crescimento urbano. Para isso, é necessário que a academia, os gestores da cidade e a população em geral tanto reconheçam os efeitos negativos do espraiamento urbano quanto vejam o adensamento populacional e a compacidade urbana como soluções seculares de gestão das cidades.

O tombamento de Brasília - pela inscrição do seu conjunto urbanístico no Livro de Tombo Histórico em 1990 - em virtude do seu excepcional valor histórico e artístico precisa se compatibilizar com as necessidades reais da cidade. Ele não pode ser interpretado como uma vedação a toda e qualquer alteração na cidade nem extrapolar a sua área de jurisdição, o Plano Piloto. Contudo, propostas de expansão urbana da cidade suscitam reações contrárias que usam o tombamento como argumento. Até mesmo a urbanização de áreas indicadas por Lucio Costa (Costa, 1987) como adequadas para a expansão urbana é constantemente criticada por supostamente ferir o tombamento. Como qualquer cidade, Brasília precisa se atualizar e favorecer os deslocamentos a pé, de bicicleta e de transporte público. 0 adensamento e compactação da cidade são elementos-chave para essa transição. Lucio Costa, em 1987, reconheceu isso ao propor o "adensamento e a expansão urbana do Plano Piloto" para solucionar a segregação socioespacial de Brasília (Costa, 1987). Como alertou Holston, é urgente resgatar o "espírito de Brasília" retomando a ousadia imaginativa de se pensar um futuro inspirado por aqueles que vivenciam a cidade (Holston, 1993, p. I-VII).

\section{Limitações da pesquisa}

Como ocorre com qualquer pesquisa, esta pode conter equívocos. Primeiramente, a delimitação do DF como área de estudo da análise diacrônica (Figura 4) pode levar à conclusão de que, com o tempo, houve uma compactação urbana em Brasília maior que a realidade. Como a concentração urbana de Brasília ocupa alguns municípios goianos (Figura 14), o ideal seria que a pesquisa diacrônica tivesse o mesmo recorte espacial da pesquisa sincrônica. No entanto, os dados disponíveis para os momentos mais antigos da análise comtemplam apenas o DF. Em segundo lugar, o uso de mapeamentos elaborados para outros estudos deixa esta pesquisa mais suscetível a erros. Além de acumular os possíveis equívocos dos mapeamentos da Unesco e do TerraClass, a unificação das legendas dessas duas pesquisas pode apresentar falhas. Além disso, é possível que uma leitura superficial associada a uma interpretação reducionista desta pesquisa conclua que acreditamos ingenuamente que a densidade e a compacidade são suficientes para garantir que a cidade seja ambientalmente correta. Não é o caso. Um cenário de crescimento urbano mais denso e compacto - como o proposto por esta pesquisa (Figura 13) - possibilitaria uma gestão urbana mais simples, uma sociedade menos segregada e uma preservação ambiental mais eficaz. Contudo, cabe aos atores envolvidos na gestão urbana se aproveitarem dessa condição favorável para transformar a possibilidade em realidade.

Finalmente, há uma literatura crítica do adensamento e da compactação ausente nesta pesquisa. Frequentemente, ela destaca os problemas socioambientais do adensamento e da compactação das cidades (Bélanger, 2017) ou defende um possível crescimento territorial da cidade mais amigável ao ambiente natural (Monte-Mór, 2015). Tal literatura, no entanto, é frequentemente orientada apenas pelo urbanismo — ou seja, com o foco antropocêntrico - e não engloba questões e análises ecológicas da passagem natural como esta pesquisa faz. Por isso, tal literatura não foi aqui abordada. 


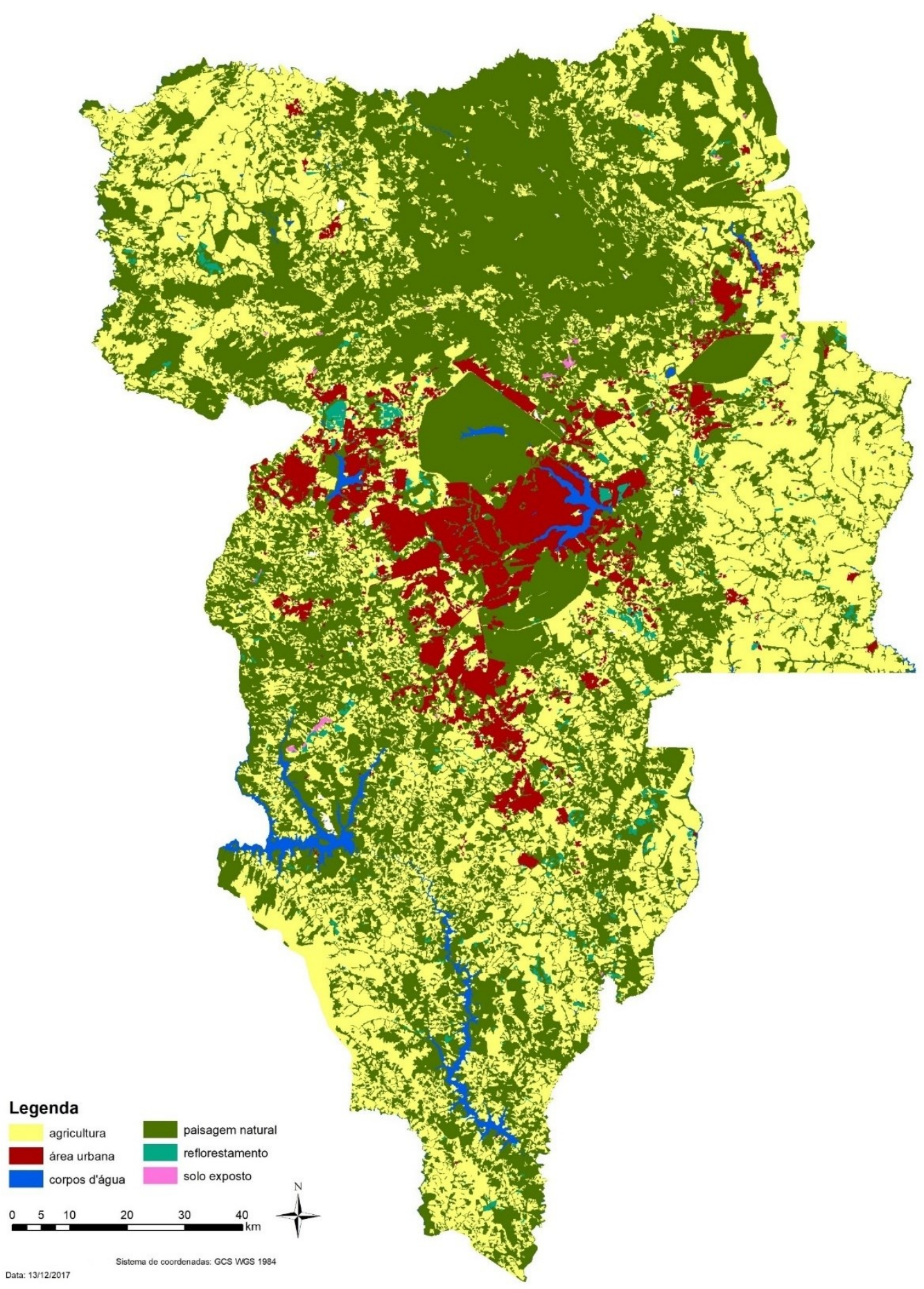

Figura 14 - Paisagem da concentração urbana de Brasília em 2013. Fonte: Elaborado pelos autores com base em Brasil (2015).

\section{Conclusões}

A construção de cidades sustentáveis depende de um conhecimento adequado acerca das características que essas cidades devem ter. Sob a perspectiva da ecologia da paisagem, a urbanização necessariamente promove uma perturbação na paisagem natural em que se insere. Assim, estudos que avaliam a sustentabilidade ambiental urbana devem abranger toda a paisagem natural ao redor da cidade, sem se limitarem a análises intraurbanas.

Este estudo de caso mostra o possível benefício ecológico do adensamento populacional urbano e da compactação urbana quando o contexto da análise inclui a paisagem ao redor da cidade. 0 espraiamento urbano aumenta as áreas verdes dentro da cidade, mas faz com que a cidade ocupe uma área significativamente maior e fragmente mais extensamente a paisagem natural ao seu redor. Assim, há perdas 
quantitativas e qualitativas para a paisagem natural remanescente: ela tem a sua área total reduzida e a sua forma fragmentada.

Embora as vantagens do adensamento e da compactação urbanos já estejam presentes no debate científico internacional, elas ainda são inexpressivas no contexto brasileiro. Espera-se que outros estudos como este busquem metodologias mais holísticas e mais precisas para se avaliar as interações entre as cidades e o meio ambiente natural. Quanto mais adequado e mais preciso for o conhecimento acerca dos impactos ambientais das cidades, maiores são as chances de sucesso do planejamento urbano futuro.

\section{Agradecimentos}

O presente trabalho foi realizado com apoio do Conselho Nacional de Desenvolvimento Científico e Tecnológico (CNPq) e da Coordenação de Aperfeiçoamento de Pessoal de Nível Superior - Brasil (CAPES) Código de Financiamento 001. Agradecemos o apoio recebido.

\section{Referências}

Bélanger, P. (2017). Landscape as Infrastructure. Nova York: Routledge.

Braga, M. (2010). O concurso de Brasília: sete projetos para uma capital. São Paulo: Cosac Naify.

Brasil. (2015). Mapeamento do uso e cobertura do Cerrado: projeto TerraClass Cerrado 2013. Brasília: MMA.

Castro, L. G. R. (2019). Densidades, formas urbanas e urbanidades. Relações de natureza complexa. Arquitextos, 19(226.02). Recuperado em 7 de dezembro de 2020, de https://www.vitruvius.com.br/revistas/read/arquitextos/19.226/7327

Codeplan. (2012). Pesquisa Distrital por Amostra de Domicílios - Distrito Federal - PDAD/DF 2011. Brasília: Codeplan. Recuperado em 26 de outubro de 2020, de http://www.codeplan.df.gov.br/pdad2011/

Costa, L. (1957). Relatório do Plano Piloto de Brasília. In M. Braga (2010). O concurso de Brasília: sete projetos para uma capital. São Paulo: Cosac Naify.

Costa, L. (1987). Brasília revisitada: complementação, preservação, adensamento e expansão urbana. Brasília: Diário Oficial do Distrito Federal. Recuperado em 26 de outubro de 2020, de http://www.sinj.df.gov.br/sinj/Diario/1d8c4f0f-a7f4-3bd9ac37-d01d9a1b7ba3/00fc9851.pdf

Dirzo, R., Young, H. S., Galetti, M., Ceballos, G., Isaac, N. J. B., \& Collen, B. (2014). Defaunation in the Anthropocene. Science, 345(6195), 401-406.

Dupras, J., Marull, J., Parcerisas, L., Coll, F., Gonzalez, A., Girard, M., \& Tello, E. (2016). The impacts of urban sprawl on ecological connectivity in the Montreal Metropolitan Region. Environmental Science \& Policy, 58, 61-73.

Epstein, D. (1973). Brasília, plan and reality: a study of planned and spontaneous developments. Berkeley e Los Angeles: University of California Press.

Farr, D. (2013). Urbanismo Sustentável: desenho urbano com a natureza. Porto Alegre: Bookman.

Ferreira, I. C. B. (2010). Brasília: mitos e contradições na história de Brasília. In A. Paviani, F. F. P. Barreto, I. C. B. Ferreira, L. C. F. Cidade, S. U. Jatobá. (orgs.). Brasília 50 anos: da capital a metrópole (pp. 23-53). Brasília: Editora UnB.

Geschke, A., James, S., Bennett, A. F., \& Nimmo, D. G. (2018). Compact cities or sprawling suburbs? Optimising the distribution of people in cities to maximise species diversity. Journal of applied ecology, 55(5), 2320-2331.

Green, R. E, Cornell, S. J., Scharlemann, J. P. W., \& Balmford, A. (2005). Farming and the fate of wild nature. Science, 307(5709), 550-555.

Holanda, F. (2001). Uma ponte para a urbanidade. Revista Brasileira de Estudos Urbanos e Regionais, (5), 59.

Holanda, F. (2010). Brasília - cidade moderna, cidade eterna. Brasília: Editora UnB.

Holanda, F. (2020). Inclusão e exclusão em Brasília. urbe, Revista Brasileira de Gestão Urbana, 12. Recuperado em 10 de dezembro de 2020, de http://www.scielo.br/scielo.php?script=sci_arttext\&pid=S2175-

$33692020000100403 \& \operatorname{lng}=\mathrm{en} \& \mathrm{nrm}=\mathrm{iso}$ 
Holston, J. (1993). A cidade modernista: uma crítica de Brasília e sua utopia. São Paulo: Companhia das Letras.

Instituto Brasileiro de Geografia e Estatística. (2012). Censo Brasileiro de 2010. Rio de Janeiro: IBGE.

Instituto Brasileiro de Geografia e Estatística. (2016). Arranjos populacionais e concentrações urbanas no Brasil. Rio de Janeiro: IBGE.

Instituto Brasileiro de Geografia e Estatística. (2017). Áreas urbanizadas do Brasil: 2015. Rio de Janeiro: IBGE.

Koster, H., Nielsen, V. M., Ostermeijer, F., \& Van Ommeren, J. N. (out. 2019) Automobiles and Urban Density. CEPR Discussion Paper No. DP14717. Recuperado em 8 de dezembro de 2020, de

https://economics.smu.edu.sg/sites/economics.smu.edu.sg/files/economics/Events/Urban2019/Urbandensity20190ct28 .pdf

Macarthur, R. H., \& Wilson, E. O. (1967). The theory of island biogeography. Princeton University Press.

Mapbiomas. (2020). Coleção 5 da Série Anual de Mapas de Cobertura e Uso de Solo do Brasil. Recuperado em 7 de dezembro de 2020, de https://plataforma.mapbiomas.org/

Monte-Mór, R. L. M. (2015). Urbanização, sustentabilidade, desenvolvimento: complexidades e diversidades contemporâneas na produção do espaço urbano. In G. M. Costa, H. S. M. Costa, R. L. M. Monte-Mór (orgs.). Teorias e práticas urbanas: condições para a sociedade urbana. Belo Horizonte: C/Arte.

Ojima, R. (2007). Dimensões da urbanização dispersa e proposta metodológica para estudos comparativos: uma abordagem socioespacial em aglomerações urbanas brasileiras. Revista Brasileira de Estudos de População, 24(2), 277-300.

Organização das Nações Unidas. (2016). Resolução 71/256: New Urban Agenda. Recuperado em 26 de outubro de 2020, de http://habitat3.org/the-new-urban-agenda/

Paviani, A. (2010). Brasília: a metrópole em crise. Brasília: UnB.

Phalan, B., Onial, M., Balmford, A., \& Green, R. E. (2011). Reconciling food production and Biodiversity Conservation: land sharing and land sparing compared. Science, 333(6047), 1289-1291.

Phalan, B., Green, R. E., Dicks, L. V., Dotta, G., Feniuk, C., Lamb, A., Strassburg, B., Williams, D., Ermgassen, E. K. H. J., \& Balmford, A. (2016). How can higher-yield farming help to spare nature? Science, 351(6272), 450-451.

Pimm, S. L., Jenkins, C. N., Abell, R., Brooks, T. M., Gittleman, J. L., Joppa, L. N., Raven, P. H., Roberts, C. M., \& Sexton, J. 0. (2014). The biodiversity of species and their rates of extinction, distribution, and protection. Science, 344(6187).

Primack, R. B.; \& Rodrigues, E. (2001). Biologia da conservação. Londrina: E. Rodrigues.

Ribeiro, E. L., \& Silveira, J. A. (2009). 0 fenômeno do sprawling urbano. Revista aU - Arquitetura e Urbanismo, 185. Recuperado em 14 de abril de 2015, de http://au.pini.com.br/arquitetura-urbanismo/185/o-fenomeno-do-sprawlingurbano-por-edson-leite-ribeiro-e-149628-1.aspx

Ross, B. (2014). Dead end: suburban sprawl and the rebirth of American urbanism. Nova York: Oxford University Press.

Speck, J. (2012). Walkable city: how downtown can save America, one step at a time. Nova York: North Point Press.

Terando, A. J., Costanza, J., Belyea, C., Dunn, R. R., McKerrow, A., \& Collazo, J. A. (2014). The southern megalopolis: using the past to predict the future of urban sprawl in the Southeast US. PloS one, 9(7), e102261.

Unesco. (2002) Vegetação do Distrito Federal: tempo e espaço. Brasília: Unesco.

Vasconcelos, A. M. N. (2010). Cenários demográficos para a Área Metropolitana de Brasília. In A. Paviani, F. F. P. Barreto, I. C. B. Ferreira, L. C. F. Cidade, S. U. Jatobá. (orgs.). Brasília 50 anos: da capital a metrópole (pp. 397-426). Brasília: Editora UnB.

Waggoner, P. E. (1996). How Much Land Can Ten Billion People Spare for Nature? Daedalus, 125(3).

Wilson, E. O. (1999). The diversity of life. WW Norton \& Company.

Wisnik, G. (2010). Apresentação. In M. Braga. O concurso de Brasília: sete projetos para uma capital. São Paulo: Cosac Naify.

Editor: Rodrigo Firmino

Recebido: 11 dez. 2020

Aprovado: 28 mai. 2021 